\title{
Habitação social e o Programa de Urbanização de Favelas: o Conjunto Paraisópolis em São Paulo
}

\author{
Ana Carolina Carvalho Figueiredo*
}

\begin{abstract}
Resumo O Programa das Nações Unidas para o Desenvolvimento aponta aproximadamente metade da população mundial vivendo nas cidades, podendo alcançar quase 60\% até 2030. Os moradores de favelas também aumentam, ultrapassando 828 milhões no mundo. São Paulo possui números elevados de moradores em favelas, requerendo atenção a programas de provisão de moradia à população carente. Este artigo apresenta a atuação do Programa de Urbanização de Favelas na cidade, destacando o projeto do Complexo Paraisópolis. Para tal, foram utilizadas as metodologias das pesquisas bibliográfica e documental e estudo de caso. O resultado aponta ações pontuais promovidas pelo município ampliando o acesso à moradia digna e infraestrutura; mas existam deficiências a serem trabalhadas para atuação mais efetiva do Estado em áreas vulneráveis.
\end{abstract}

Palavras-chave: habitação social, favela, São Paulo.

\section{Vivienda social y el Programa de Urbani- zación de Favelas: el complejo Paraisópolis, en São Paulo}

Resumen El Programa de las Naciones Unidas para el Desarrollo designa a aproximadamente la mitad de la población mundial vive en ciudades, alcanzando casi el 60\% para 2030. Los habitantes de barrios marginales también están aumentando, superando los 828 millones. São Paulo tiene un gran número de habitantes de tugurios, requiriendo atención a los programas de provisión de vivienda. Este artículo presenta el desempeño del Programa de Urbanización de Favelas, destacando el proyecto "Complejo Paraisópolis". Para ello se utilizaron las metodologías de investigación bibliográfica y documental y estudio de casos. El resultado apunta acciones del municipio, ampliando el acceso a vivienda e infraestructura; pero existen deficiencias que deben ser abordadas para que el Estado actúe con mayor eficacia en áreas vulnerables.

Palabras clave: vivienda social, favela, São Paulo.

\section{Social housing and the Favela Urbaniza- tion Program: the Paraisópolis complex, in São Paulo}

\begin{abstract}
The United Nations Development Programme appoints approximately half of the world population living in cities, reaching almost $60 \%$ by 2030 . Slum dwellers are also increasing, exceeding 828 million in the world. São Paulo has high numbers of slum dwellers, requiring attention to housing provision programs for the poor. This article presents the performance of the Favela's Urbanization Program in the city, highlighting the Paraisópolis Complex project. For this, the methodologies of bibliographic and documentary research and case study were used. The result points to specific actions promoted by the municipality, expanding access to decent housing and infrastructure; but there are deficiencies to be addressed for the State to act more effectively in vulnerable areas.
\end{abstract}

Keywords: social housing, shanty town, São Paulo. 
D

ados do Programa das Nações Unidas para o Desenvolvimento (PNUD) assinalam que metade da população humana - cerca de 3,5 bilhões de pessoas - vive nas cidades e que esse número pode chegar a quase $60 \%$ em 2030. Outro aumento significativo, entretanto, está no número de habitantes das favelas: estima-se que os já 828 milhões, continuem crescendo. Tanto quanto enormes problemas sociais, tais estimativas colocam em pauta uma crescente pressão na oferta de água potável, geram aumento efetivo na produção de esgoto, no consumo de energia e recursos; de forma geral, torna crescentes as tensões entre ambiente e saúde pública.

Quando concentra-se esses índices no Brasil, percebe-se que a realidade é tal qual o panorama mundial. Conforme apontou o IBGE (2018), em 2010 a taxa da população brasileira vivendo em áreas urbanas já era cerca de $80 \%$. Há, em parte das moradias das cidades, contudo, problemas ligados à precariedade dos assentamentos. Muitos deles se caracterizam pela deficiência de infraestrutura e de serviços e sistemas de transporte eficientes; pela irregularidade fundiária; pelos altos níveis de insegurança e de densidade. Muitos não dispõem de iluminação elétrica, coleta de lixo, acesso às redes de distribuição e abastecimento e esgotamento sanitário adequado. Assim, elas ainda não atendem plenamente alguns requisitos mínimos de qualidade.

De qualquer modo, no país como um todo, desde os anos 1990 algumas importantes ações nas favelas começaram a ser efetivadas. Até o início dos anos 2000, aproximadamente oito mil famílias foram atendidas (DENALDI, 2003). É neste contexto que se insere o Programa de Urbanização de Favelas da cidade de São Paulo, o qual a atuação será destacada aqui na primeira década do século XXI, sobretudo pela atuação na área da favela de Paraisópolis.

Estas considerações apresentadas no artigo foram extraídas de excertos da dissertação de mestrado "Certificação ambiental e habitação no Brasil: agentes e requisitos urbanísticos e arquitetônicos"1 o panorama da habitação. Tratando-se de uma pesquisa qualitativa e exploratória, utilizam-se, aqui, as pesquisas bibliográfica e documental em primeiro momento e; posteriormente, o Estudo de caso, empregando ferramentas de pesquisa bem como entrevistas e visita de campo que ajudaram a delinear a proposta da Secretaria de Habitação do município para a segunda maior favela da capital paulista.

* Ana Carolina Carvalho Figueiredo é Arquiteta e Urbanista, Professora da Universidade Anhanguera do $A B C(U N I A B C)$, ORCID <https://orcid.org/00000002-1776-6470>.

\section{A cidade de São Paulo e a habitação}

O panorama da formação da cidade de São Paulo bem como seu crescimento e o aumento da demanda por habitação não se descola totalmente do ocorrido no Brasil como um todo. O processo de urbanização do território brasileiro levava às cidades desde o final do século XIX, a elite rural que migrava para a vida urbana e, junto a ela, as camadas mais populares da população (SAMORA, 2010). 
1 Dissertação de mestrado defendida em agosto de 2018 no Instituto de Arquitetura e Urbanismo de São Carlos- Universidade de São Paulo, parcialmente financiado pelo CNPq.
Em São Paulo, o final do século XIX foi marcado pela transferência da matriz fundiária do meio rural para o urbano, ligada à atividade cafeeira. Em decorrência disso houve aumento populacional e maior demanda por infraestrutura e moradia. Parte dos novos moradores, que não tinha recursos para adquirir propriedades, se instalou em cortiços, casas de aluguel e moradias autoconstruídas - muitas vezes insalubres e de forma irregular. E esse cenário de desigualdades se intensificou com o passar dos anos (WERNECK, 2016; CASTILHO, 2013).

Conforme apontado pela Prefeitura Municipal de São Paulo (2008), a cidade possui uma estrutura viária radial herdada das rotas rumando o interior e o litoral do estado, dado seu posicionamento estratégico. Esta estrutura serviu de base para as diversas ocupações e expansões da malha urbana que se deram a partir dos anos 1950, inclusive aquelas em direção à periferia da cidade. As casas, em geral autoconstruídas, em locais carentes de serviços e equipamentos configuravam o que era chamado de "urbanização sem cidade".

A autoconstrução, inclusive, foi uma das principais formas de acesso à moradia da população mais pobre na cidade de São Paulo entre os anos de 1940 e 1970. Inicialmente, essa população se instalou nas áreas centrais de onde, posteriormente, foram expulsas passando a ocupar as regiões mais periféricas - incluindo áreas de morros, pântanos e próximas a ferrovias (SAMORA, 2010).

Castilho (2013) destaca que as intervenções ocorridas por volta de 1960, sob o discurso de higienização e controle de doenças nos aglomerados urbanos precários, buscavam remover a população dessas áreas. Alguns anos depois, na década de 70 tornou-se claro que, em grande parte, os moradores realocados para conjuntos habitacionais tradicionais e distantes abandonavam-nos e retornavam às favelas. Assim, o problema estava longe de ser solucionado.

De acordo com Castilho (2013) a Lei Federal 6.766, de 1979, regulamentou a implantação de loteamentos. Mas com a rigidez das regras, as invasões e a formação de favelas se intensificou, onde essas áreas irregulares se colocaram cada vez mais às margens dos investimentos em habitação.

Samora (2010), por sua vez, elaborou uma "linha do tempo" de ações do poder público municipal sobre os aglomerados urbanos considerados como favelas na cidade de São Paulo. Um primeiro momento para autora vai dos anos 1960 a 1980 em que o poder público encara a favela como um problema cuja única solução implicava total remoção da população daquela determinada área. Enquanto isso, em segundo momento, se encontra a gestão da prefeita Luiza Erundina - entre 1989 e 1992 quando se criou o "Programa de Habitação de Interesse Social" que foi responsável por ampliar a alocação de recursos para este setor e, ainda, trabalhar na regularização de áreas de favelas.

O terceiro período vai de 1992 a 2000 quando, pelas gestões de Maluf e Pitta, foram criados grandes programas voltados para a habitação social com recursos de entes internacionais tais como Banco Interamericano de Desenvolvimento (BID). Dentre os principais programas criados estão o Guarapiranga, Cingapura ou PROVER e o Programa de Canalização de Córregos (PROCAV). 
Os principais problemas apontados no que se refere a estes programas envolvem a remoção da população para novas unidades desconsiderando a ocupação prévia; a falta de integração entre a favela e a cidade existente; a alta prestação das unidades que comprometia a renda da população; a irregularidade fundiária que permanecia; e, problemas relativos à tipologia da habitação que, normalmente, não atendia à necessidade da população - os $42 \mathrm{~m}^{2}$ eram insuficientes para as famílias mais numerosas.

Um quarto momento assinalado corresponde aos anos de 2001 e 2004 em que o governo de Marta Suplicy foi responsável pela criação dos programas Bairro Legal voltado para a requalificação urbana - e Morar Perto - que se voltava à produção de habitação tanto próxima às áreas do centro histórico paulistano quanto de centralidades regionais. Esta política foi parcialmente mantida entre os anos de 2005 e 2009 quando Serra e Kassab assumiram a Prefeitura Municipal. Alguns retrocessos foram observados, entretanto, este período coincidiu com um momento em que as diretrizes propostas pelo Ministério das Cidades ficavam mais claras (após sua criação em 2003).

Kassab geriu a cidade de São Paulo entre 2006 e 2012 atuando na habitação de forma ambígua. Buscava, em algumas áreas, a remoção de aglomerados com repressão e violência e, em outras, deu continuidade à programas tais como o Bairro Legal (SAMORA, 2010).

Considerando as informações apresentadas, os programas habitacionais do Município de São Paulo para atendimento de moradias de interesse social e os atores envolvidos nesses processos, sobretudo nos últimos anos, o item a seguir analisa especificamente o Programa de Urbanização de Favelas e sua atuação na cidade.

\section{Os programas de urbanização de favelas na capital paulista}

Para Magalhães e Villarosa (2012) os assentamentos precários presentes nas metrópoles do Brasil são resultado de dinâmicas que limitam o acesso à terra urbanizada e refletem a estrutura econômica e social de grandes desigualdades, ao longo da história do pais. Embora possuam elementos em comum, os assentamentos irregulares ou favelas têm suas particularidades, variando em dimensão, densidade, localização, grau de ilegalidade, qualidade construtiva, integração, risco e nível de consolidação.

Considerando esse panorama, Denaldi (2003), assinala que

Na década de 1990, a urbanização de favelas deixa de ser promovida por meio de 'programas alternativos' e passa a ser objeto de política habitacional. Constata-se o protagonismo do município. A maioria dos municípios que apresenta favelas passa a desenvolver programas de urbanização e regularização como parte integrante da política municipal de habitação. São eles os responsáveis pelas maiores parcelas de investimento na área habitacional. Alguns municípios priorizam os programas de urbanização colocando-os no centro de sua política habitacional (...). (DENALDI, 2003, p. 190)

Segundo a autora, nos anos 1980, a cidade de São Paulo sob a administração do Prefeito Mário Covas, apresentou algumas experiências voltadas à reurbanização de favelas que buscavam manter a população reassentada próxima a esses núcleos. 
2 Informações fornecidas em entrevista à autora por FRANÇA e DINIZ em dez. 2017.
Durante a gestão da prefeita Luiza Erundina (1989-1992), o município vislumbrou a estruturação do primeiro programa municipal de urbanização de favelas. Nesse período, a alocação de recursos do município para o atendimento de uma parcela expressiva da população que vivia nesses aglomerados foi uma das características marcantes.

Também naquele momento, mais precisamente em 1992, o "Programa Guarapiranga" foi elaborado buscando incorporar-se ao Programa de Qualidade da Água e Controle da Poluição Hídrica em Áreas Metropolitanas - que priorizava o controle de qualidade da água, recuperação do manancial e implantação de um sistema integrado da bacia hidrográfica de mesmo nome.

Na gestão posterior, contudo, o prefeito Paulo Maluf (1993-1996) priorizou as ações de remoção das favelas de suas regiões de origem, como por exemplo o projeto realizado na área da Água Espraiada. Celso Pitta, ao assumir a Prefeitura de São Paulo (19972001), seguiu uma política voltada às favelas bastante semelhante à da gestão anterior.

Destaca-se que os anos 1990 foram um período crítico para as favelas paulistanas. Neste momento, a necessidade por urbanização e infraestrutura se ampliou, dado o aumento significativo do número de moradores vivendo em tais condições².

Naquele horizonte, a cidade apostou em programas voltados para proteção das áreas de mananciais e ambientalmente frágeis. As primeiras ações tinham o desafio de fazer com que urbanização e política habitacional caminhassem juntas e a moradia também fosse sinônimo de acesso à infraestrutura - evitando a ideia que Samora (2010) assinala como "habitação sem cidade".

De acordo com a Prefeitura da Cidade de São Paulo (2008), no ano de 1999, o Programa das Nações Unidas para os Assentamentos Humanos (UN-HABITAT) e o Banco Mundial, juntos, foram responsáveis pelo lançamento da "Aliança de Cidades" (Cities Alliance). A intenção era auxiliar, nos países em desenvolvimento, o enfrentamento de desafios tais como o crescimento das favelas e a necessidade de sustentabilidade socioambiental em pequenas e grandes cidades. Segundo o Programa, urbanizar as favelas de forma bem-sucedida requer um conjunto de requisitos. Muitas vezes, buscar soluções rápidas com abrangência, obscurece as decisões práticas de escolha de terrenos, implantação de infraestrutura e reorganização das prioridades do ponto de vista da administração pública,

A cidade de São Paulo foi parceira da Aliança durante pelo menos sete anos quando foram realizados programas como o Guarapiranga e a proposta do Bairro Legal. Em gestões posteriores, entretanto, a cooperação perdeu sua força. Mesmo assim, esse período foi marcado por ações que contribuíram com a construção de um sistema de informação que cadastrou os assentamentos informais da cidade, auxiliando na formulação do plano estratégico para habitação.

Mais uma vez, as ações se intensificaram com a criação do Estatuto das Cidades em 2001 e do Ministério das Cidades em 2003 quando os municípios puderam adquirir o protagonismo nas estratégias de gestão urbana - inclusive com a elaboração de Planos Diretores, ampliando sua atuação por meio de políticas de habitação locais, tais como no caso do Programa de Urbanização de Favelas que contemplou áreas como 
as de Paraisópolis. O Plano Diretor Estratégico do Município de São Paulo, inclusive, foi instituído em 2002 com diretrizes para melhoria da situação habitacional na cidade (RIBEIRO, 2007).

Samora (2010) aponta que a partir da regulamentação do setor habitacional e de uma política federal clara priorizando os assentamentos precários, o município passou a contar com um considerável aumento dos recursos para a habitação social e urbanização de favelas, com origens nas três esferas de governo, incluindo o PAC - Plano de Aceleração do Crescimento do governo federal. Favelas como Vila Nova Jaguaré, Heliópolis e Paraisópolis, por exemplo, estão entre as beneficiadas por recursos federais e estaduais, além dos municipais, algo até então inédito na cidade. Estas duas gestões resgataram a política do PROVER quanto ao financiamento da provisão habitacional para favelas, desta vez efetuado pela CDHU.

Pizarro (2014), em sua dissertação, sobre o Programa de Urbanização de Favelas na cidade de São Paulo, destaca que o valor investido foi cerca de 3,8 bilhões de reais, em sua maioria, proveniente do município (71\%). No total, estimava-se melhorias em 174 mil habitações das quais mais de 21 mil seriam novas construções. O programa dava prioridade às obras voltadas para infraestrutura, saúde e áreas de risco e vulnerabilidade.

São Paulo apresenta, segundo dados da Secretaria Municipal de Habitação da Prefeitura Municipal de São Paulo (2018), 1.709 favelas cadastradas onde se encontram cerca de 391.043 domicílios. Para a PMSP (2018) os principais desafios enfrentados pelas políticas habitacionais são o custo elevado da terra para novas construções - uma vez que há grande escassez de terrenos urbanos formais; a baixa capacidade de acesso das famílias a financiamentos habitacionais posto que suas rendas estão abaixo de 3 salários mínimos; e a presença de facções criminosas urbanas que atrapalham o desenvolvimento dos programas dentro das favelas. Outros desafios incluem articular as intervenções no território de modo que elas sejam condizentes com o saneamento ambiental; integrar, educar e treinar a mão-de-obra que atuará nesse processo e, ainda, a população que ocupará; e prezar pela participação popular nos processos de produção habitacional.

\section{O Complexo de Paraisópolis}

\section{O bairro de Paraisópolis}

Fernandes (2015) caracteriza Paraisópolis como um loteamento irregular cuja ocupação se iniciou na década de 1920 com o parcelamento da antiga Fazenda Morumbi que gerou 2.200 lotes. Devido à dificuldade de acesso e de instalação de infraestrutura dada sua topografia acidentada, presença de rios recortando o terreno e necessidade de transposição do rio Pinheiros para sua ocupação; aos poucos esses lotes foram deixados de lado por seus proprietários. Assim, a posse por parte de grileiros e posseiros foi facilitada, sobretudo na segunda metade do século XX com a migração de famílias japonesas e nordestinas. Nos anos 1960, esse processo se intensificou e em 1968, a Prefeitura Municipal oficializou os logradouros do local como pertencentes à cidade de São Paulo.

Com a instalação do estádio do São Paulo Futebol Clube no bairro vizinho, a abertura da Avenida Giovanni Gronchi e a mudança da sede do Governo do Estado para o 
Figura 1: Imagem aérea do contraste entre a favela de Paraisópolis e o bairro do Morumbi. Acima, a Marginal Pinheiros. Fonte: Google Earth, 2018.

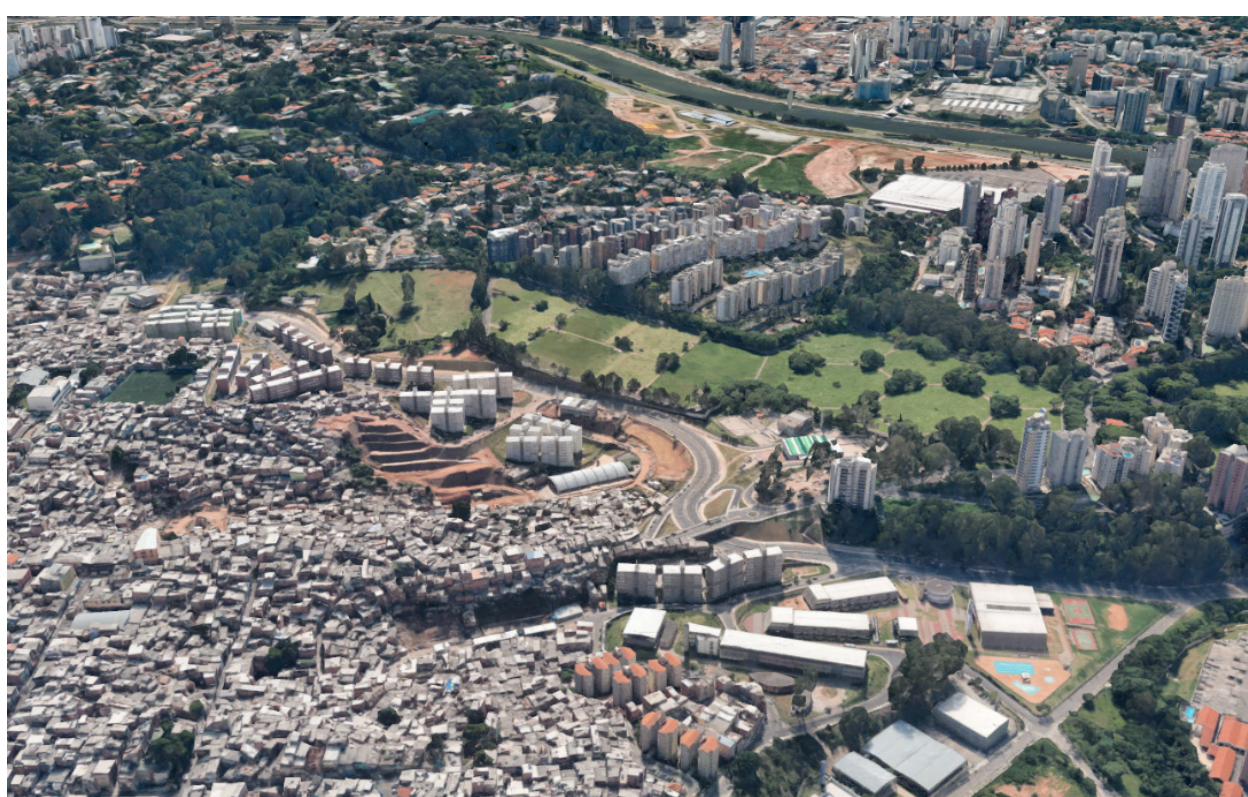

Palácio dos Bandeirantes o processo se ampliou. Ele veio como resultado do aumento da especulação imobiliária na região como um todo o que "expulsava" a população com menor renda para as áreas mais insalubres. Atualmente, a área pertence ao distrito da Vila Andrade e à subprefeitura do Campo Limpo, apresentando um dos entornos mais ricos da cidade.

Pizarro (2014) destaca o enorme contraste entre Paraisópolis e seu entorno, conforme é possível vislumbrar na figura 1. A posição da favela é, de acordo com o autor, emblemática pois sua "colocação" ao lado de um dos bairros mais luxuosos da cidade de São Paulo - o Morumbi - reforça a desigualdade econômica e social.

Em 2002, com o Plano Diretor Estratégico, a região de Paraisópolis foi definida como Zona Especial de Interesse Social (ZEIS 1) onde prevalecem loteamentos irregulares e população de baixa renda (FERNANDES, 2015).

Pizarro (2014) realiza um diagnóstico de que o assentamento é, definitivamente, um local consolidado e não provisório. Os materiais e técnicas construtivas que ali se empregam, os serviços e sinais de infraestrutura urbana existentes, bem como a diversidade de atividades presentes deixa claro que ali há um "organismo urbano" (p. 101). Mais do que isso, a dimensão populacional de Paraisópolis supera, muitas vezes, a maioria dos municípios do Estado de São Paulo com seus mais de 100 mil habitantes. A área ocupada pela favela é relativamente pequena, o que a torna densa - com cerca de 490 hab/ha.

A região tem sido cenário para intervenções urbanas por parte da Prefeitura Municipal de São Paulo desde 2008.

Os projetos para a urbanização da favela de Paraisópolis se inserem em um contexto em que a Prefeitura Municipal de São Paulo contava com uma equipe entusiasmada e 
${ }^{3} \mathrm{~A}$ informação aqui assinalada foi retirada de trechos da entrevista concedida à autora em dezembro de 2017 pelas arquitetas da SEHAB responsáveis pela coordenação dos projetos de urbanização em Paraisópolis.

Figura 2: Conjunto Paraisópolis: condomínios, escola e ciclovias. Fonte: Foto da autora, 2017.

Figura 3: Favela de Paraisópolis: condomínios e ginásio esportivo. Fonte: Foto da autora, 2017. jovem, pronta para atuar na proposição de novas unidades habitacionais para reassentar famílias que moravam nas áreas de risco. O local em si possui diversas áreas de risco e uma grande dificuldade de se encontrar terrenos disponíveis ${ }^{3}$.

\section{Projeto de Urbanização: o Complexo Paraisópolis}

Em 2003, foi estabelecido que a Secretaria de Habitação e Desenvolvimento Urbano através da figura da Superintendência de Habitação Popular se responsabilizaria por apresentar um Plano de Urbanização para o Complexo de Paraisópolis, a segunda maior favela de São Paulo - perdendo apenas para o aglomerado de Heliópolis.

No Programa de Urbanização da Favela de Paraisópolis foram previstas três fases de urbanização com custo total de 529 milhões de reais destinados para projetos de novas unidades habitacionais, equipamentos de saúde, cultura, educação, áreas livres, saneamento básico e infraestrutura viária (PIZARRO, 2014).

Nas figuras 2 e 3, que se seguem, é possível vislumbrar alguns dos equipamentos instalados nessa área: escolas, ginásio de esportes e ciclovias, bem como algumas melhorias do ponto de vista das vias do entorno.

4 Informações fornecidas em entrevista à autora por FRANÇA e DINIZ em dez. 2017.
5 Informações fornecidas em entrevista à autora por FRANÇA e DINIZ em dez. 2017.

6 É importante salientar que, outras publicações também assinalam a necessidade de garantir, nas intervenções urbanas em aglomerados precários, o reassentamento das famílias em locais na própria área de origem ou próximas (BRASIL, 2010).

Figura 4: Parque infantil do Condomínio G. Fonte: Foto da autora, 2017.
A Secretaria realizou, inicialmente, três licitações de obras para as intervenções no local e buscou, sobretudo, minimizar ao máximo o número de pessoas retiradas de suas moradias ${ }^{4}$. Segundo a Prefeitura Municipal (SÃO PAULO, 2010), o projeto para Paraisópolis era estratégico para a SEHAB, uma vez que tratava-se na segunda maior favela da capital paulista. Com o amparo legal do Estatuto das Cidades (Lei Federal no 10.257/01), justificou-se o investimento nessa Zona Especial de Interesse Social.

A comunidade está dividida em cinco áreas: Centro, Grotão, Grotinho, Brejo e Antonico. Ao Norte, Paraisópolis faz limite com outras duas favelas paulistanas: Jardim Colombo e Porto Seguro.

A primeira licitação para projetos na área ocorreu no ano de 2005, envolvendo as obras mais urgentes e que pudessem preparar a infraestrutura para uma segunda etapa de intervenções ${ }^{5}$. A ideia sempre foi manter as famílias em terrenos localizados na própria comunidade uma vez que esta foi, desde o início, uma demanda da população ${ }^{6}$.

Contudo, uma das maiores dificuldades encontradas para garantir que as famílias removidas fossem reassentadas na região foi a ausência de áreas públicas, que não estivessem nas áreas de risco e de mananciais. Uma das etapas do trabalho realizado pela SEHAB na região, então, envolveu a compra de diversos terrenos juntamente com o desenvolvimento dos projetos de urbanização.

De acordo com Silva (2017), os projetos do Programa de Urbanização de Paraisópolis são parte de uma ação de urbanização cujo discurso assinala a necessidade de integração da favela à cidade formal, com regulação urbanística e fundiária, infraestrutura e melhorias nas condições sanitárias, ambientais e de habitabilidade. Essas obras, inclusive, seriam expandidas tanto para as comunidades adjacentes do Jardim Colombo e Porto Seguro.

Para tal, houve parceria entre um conjunto grande de atores - Prefeitura Municipal de São Paulo, SABESP e Eletropaulo; com financiamentos do Fundo Municipal de

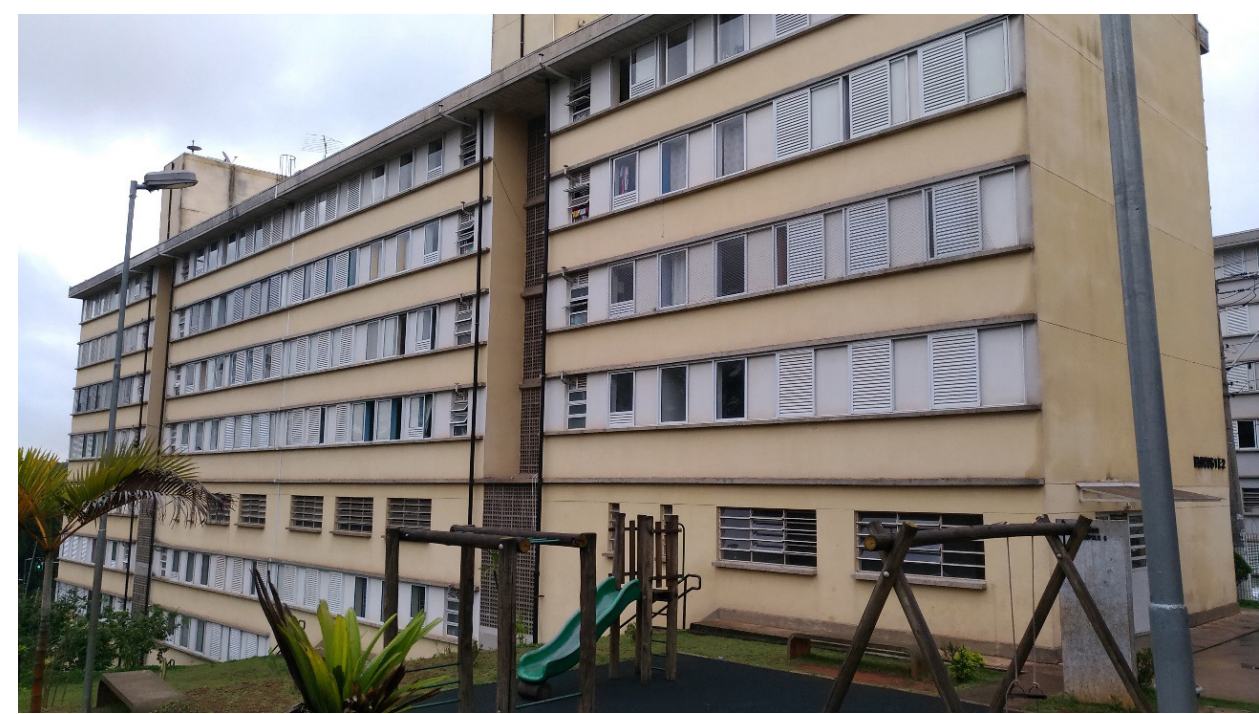


Figura 5: Pavimentação da Avenida Hebe Camargo e implantação da ciclovia. Fonte: Foto da autora, 2017.

\begin{abstract}
7 Deve-se lembrar que o Programa de Verticalização de Favelas (PROVER) era mais conhecido como Projeto Cingapura e se iniciou em 1993 no município de São Paulo atuando ainda no período imediatamente anterior ao início dos projetos da SEHAB para Paraisópolis (PREFEITURA MUNICIPAL DE SÃO PAULO, 2018).
\end{abstract}

8 Informações obtidas em entrevista concedida à autora por FRANÇA e DINIZ em dez. 2017.

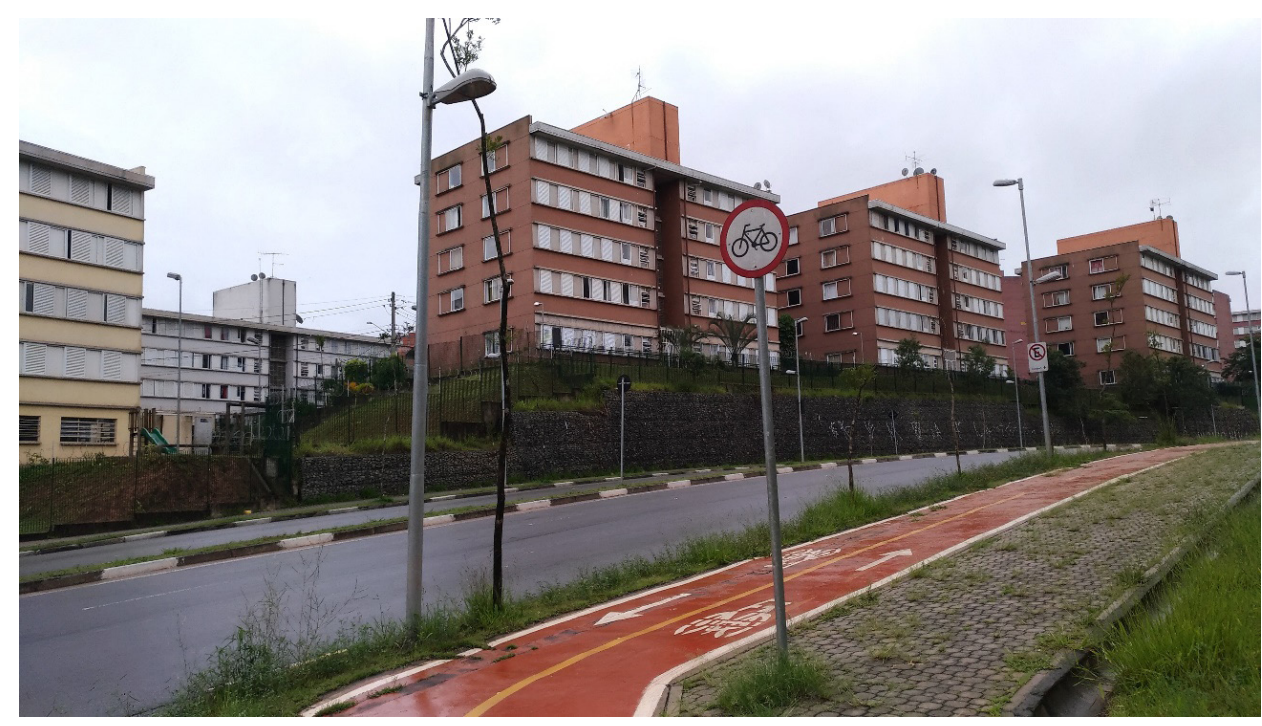

Saneamento Ambiental e Infraestrutura (FMSAI), da Companhia de Desenvolvimento Habitacional e Urbano (CDHU) e do Fundo de Desenvolvimento Urbano (FUNDURB). A meta era que o projeto envolvesse mais do que a criação de habitação, obras de canalização de cursos d'água, contenção e estabilização de taludes, implantação de áreas verdes e equipamentos públicos.

As obras realizadas entre os anos de 2008 e 2013 compreendem, assim, os conjuntos habitacionais localizados na área do Grotão, creches, centros comunitários, estabelecimentos comerciais, postos de saúde, áreas de assistência social, obras de drenagem, pavimentação, saneamento básico e acessibilidade (FERNANDES, 2015).

O momento de implantação dos conjuntos no Complexo de Paraisópolis coincidiu com a revisão das diretrizes gerais de projeto da SEHAB que buscava melhorar o modelo corrente dos "Cingapura"7. A construção de Habitação de Interesse Social (HIS) naquele período "significava dizer quantos 'Cingapuras' cabiam" na área que receberia o projeto. Este modelo de moradia corrente na cidade de São Paulo até então, se constituía de um módulo usualmente carimbado nos terrenos em uma determinada área (a figura 6 a seguir é um típico exemplo do modelo de habitação em favelas proposta pela Prefeitura Municipal de São Paulo). Mas a SEHAB não pretendia implantar este modelo no projeto de Paraisópolis ${ }^{8}$.

Então Paraisópolis foi o primeiro projeto que foi elaborado que não era Cingapura no momento e a gente tava numa intenção muito forte de melhorar a qualidade dos projetos. Então ele já entrou com várias melhorias em relação ao Cingapura como por exemplo o gás no chuveiro e no fogão, as janelas que corriam para fora com abertura de $100 \%$ de ventilação e iluminação; o telhado que era com cores claras também pra não existir problemas com calor. E (...) não tinha Minha Casa Minha Vida, não tinha nada. Essa era uma intenção da própria SEHAB de melhorar seus projetos. (FRANÇA, informação verbal, 2017) 
Figura 6: Edifícios do programa PROVER ou Cingapura na favela São Jorge Arpoador. Fonte: $<$ http://www.prodam.sp.gov.br/ invfut/cinga/cinga4.htm>.

9 Esta informação foi fornecida em entrevista concedida à autora em dezembro de 2017 pelas arquitetas da SEHAB que coordenaram o Programa de Urbanização em Paraisópolis.

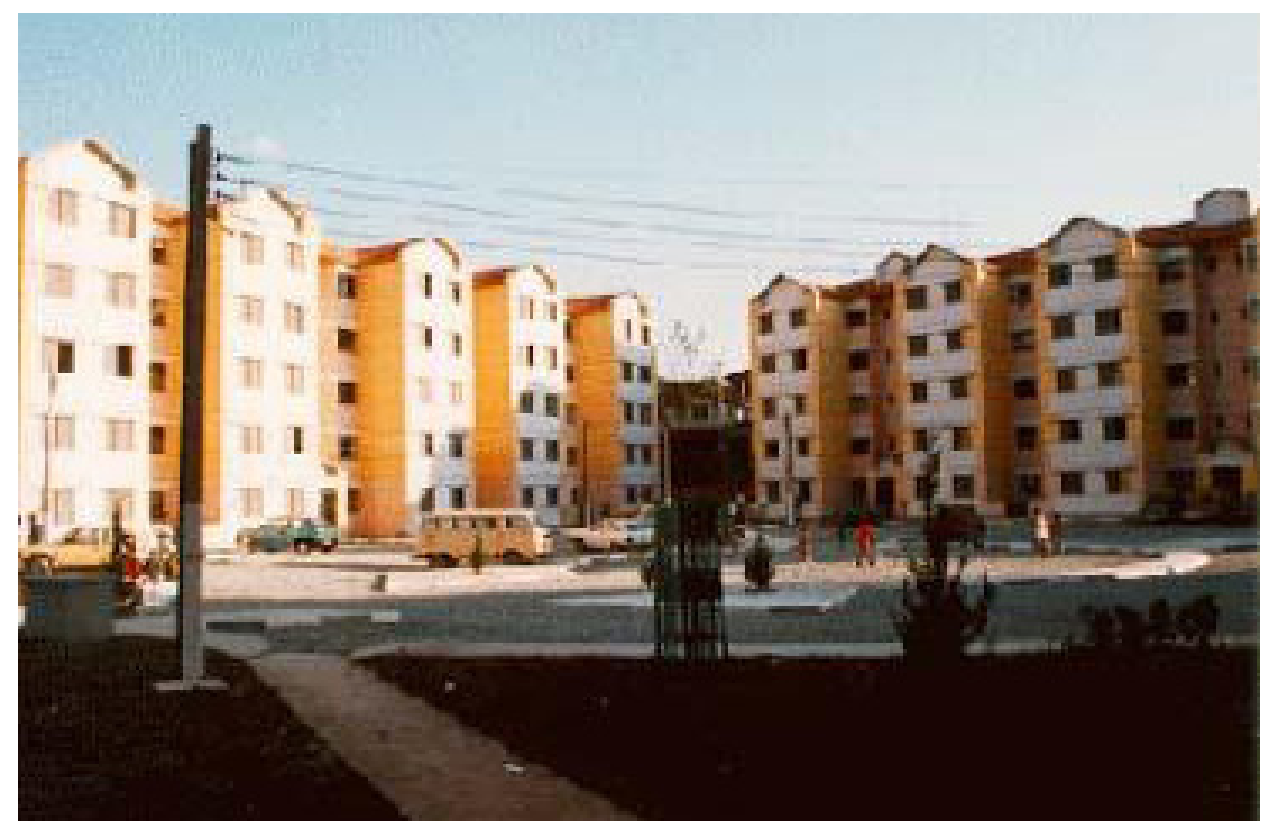

O Complexo de Paraisópolis, especificamente, cuja construção se iniciou em 2008 para abrigar famílias de baixa renda removidas da própria região, de áreas de maior risco ambiental e social, é constituído por onze condomínios - sendo sete deles projetados pelo escritório Elito Arquitetos. Ao todo, foram construídas 1.229 unidades habitacionais na intervenção que finalizou em 2013. Neste período, também foram realizadas obras de infraestrutura, urbanização, paisagismo, áreas comerciais e institucionais (FERNANDES, 2015).

O terreno onde foram implantados os condomínios corresponde a uma área adjacente à favela, anteriormente livre e não urbanizada - um terreno "bom e caro" - foi comprado pela Prefeitura Municipal de São Paulo para a implantação do projeto 9 .

As primeiras unidades habitacionais foram entregues entre setembro de 2009 e março de 2011 (Condomínios A, B, C, D e F), somando um total de 783 novas moradias. Os Condomínios E e G, por sua vez, fizeram parte da terceira etapa das obras cujos recursos empregados vieram do Programa de Aceleração do Crescimento (PAC - Caixa Econômica Federal), SABESP, SEHAB, FUNDURB e Fundo de Saneamento (SILVA, 2017).

O Quadro 1 a seguir apresenta as principais características dos conjuntos habitacionais implantados no Complexo Paraisópolis no que se refere à tipologia e área total, sobretudo. Neste quadro ainda encontra a área útil das unidades comerciais presentes em algumas das edificações deste conjunto.

A figura 7 traz o pavimento térreo de um dos Condomínios de Paraisópolis, em que podem ser identificadas tanto as unidades habitacionais como áreas que correspondem ao espaço comum das edificações. A figura 8 apresenta uma imagem do interior de um apartamento inserido no Condomínio G. 
Quadro 1 (topo): Características dos Condomínios projetados pelo escritório Elito Arquiteto. Fonte: Elaboração própria a partir de Elito Arquitetos, 2018.

Figura 8 (centro): Interior do apartamento do Condomínio G, após ocupação. Fonte: Foto da autora, 2017.

Figura 7 (embaixo): Planta do pavimento térreo (tipo), na entrega. Fonte: Elito Arquitetos, 2018.

\begin{tabular}{ll}
\hline TIPOLOGIA CONECTÁVEL & CONDOMÍNIOS A, B, C, E, F E G \\
\hline ÁREA TOTAL & $54,45 \mathrm{~m}^{2}$ \\
\hline TIPOLOGIA ISOLADA & CONDOMÍNIO D \\
\hline ÁREA DA UNIDADE COMERCIAL & $13,47 \mathrm{~m}^{2}$ \\
\hline ÁREA CONSTRUÍDA & $66.300 \mathrm{~m}^{2}$ \\
\hline
\end{tabular}

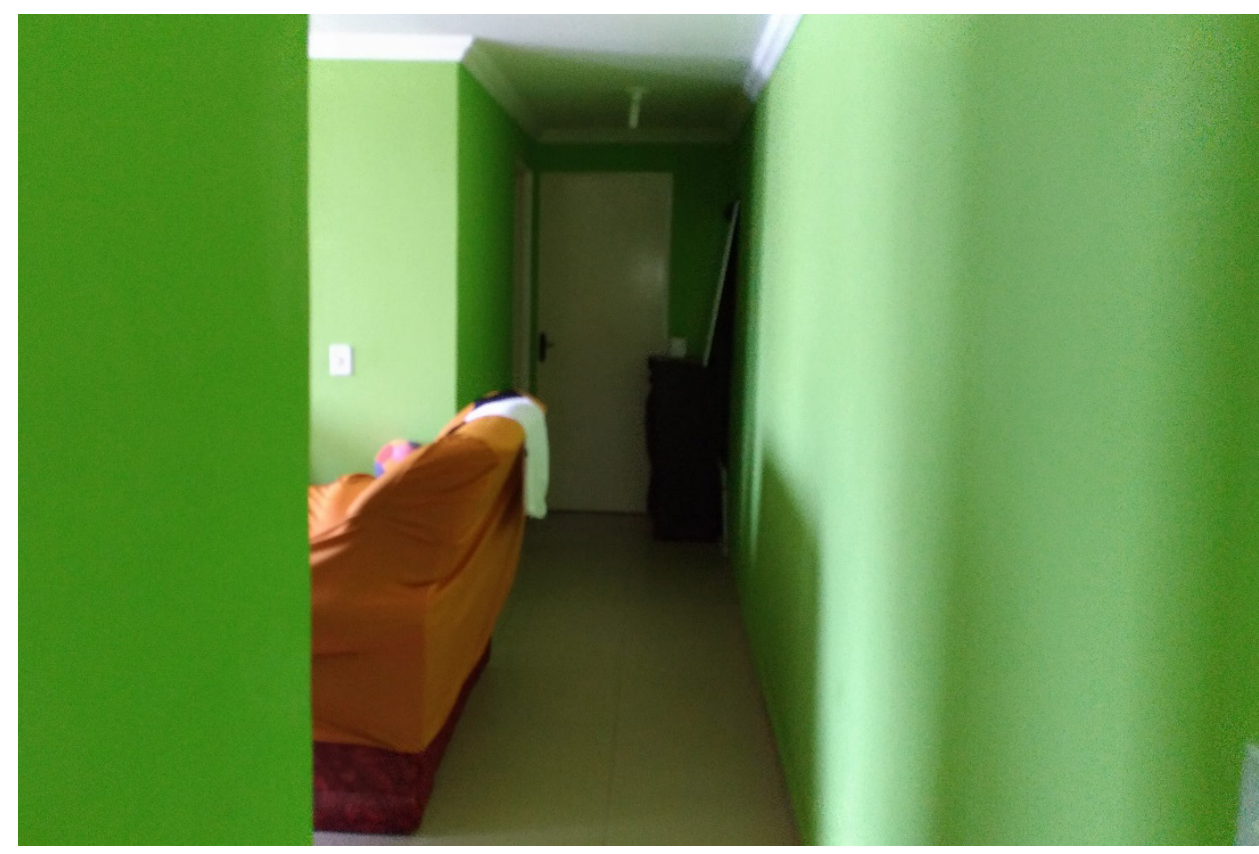

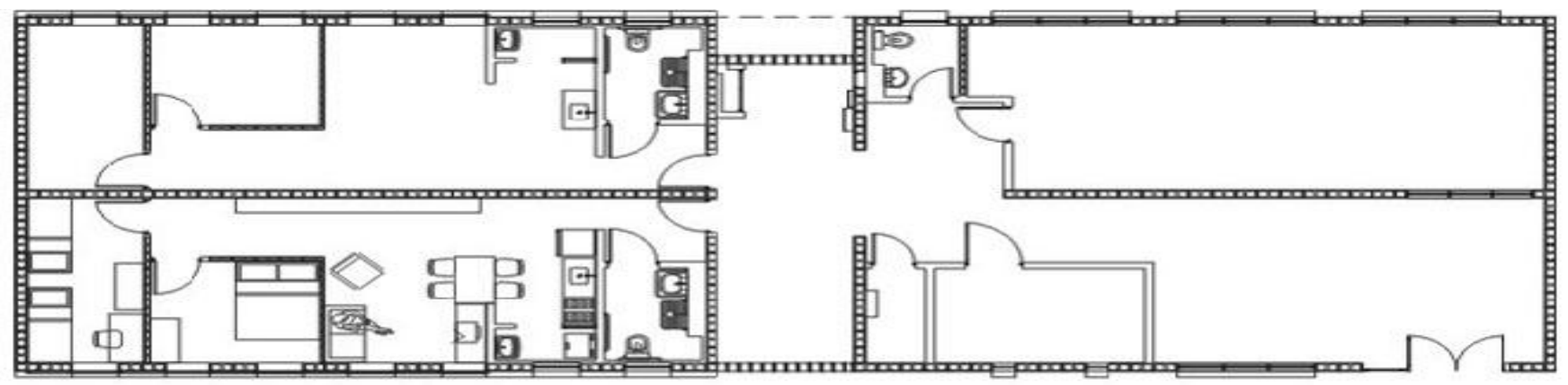

PLANTA PAVIMENTO TERREO

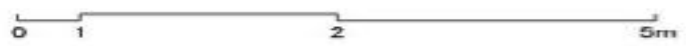


Figura 9: Área de reuniões para o condomínios. Fonte: Foto da autora, 2017.

10 Dados fornecidos em entrevista concedida à autora em outubro de 2017 por um dos arquitetos do Escritório Elito Arquitetos responsável pelo projeto dos Condomínios A a G, em Paraisópolis.

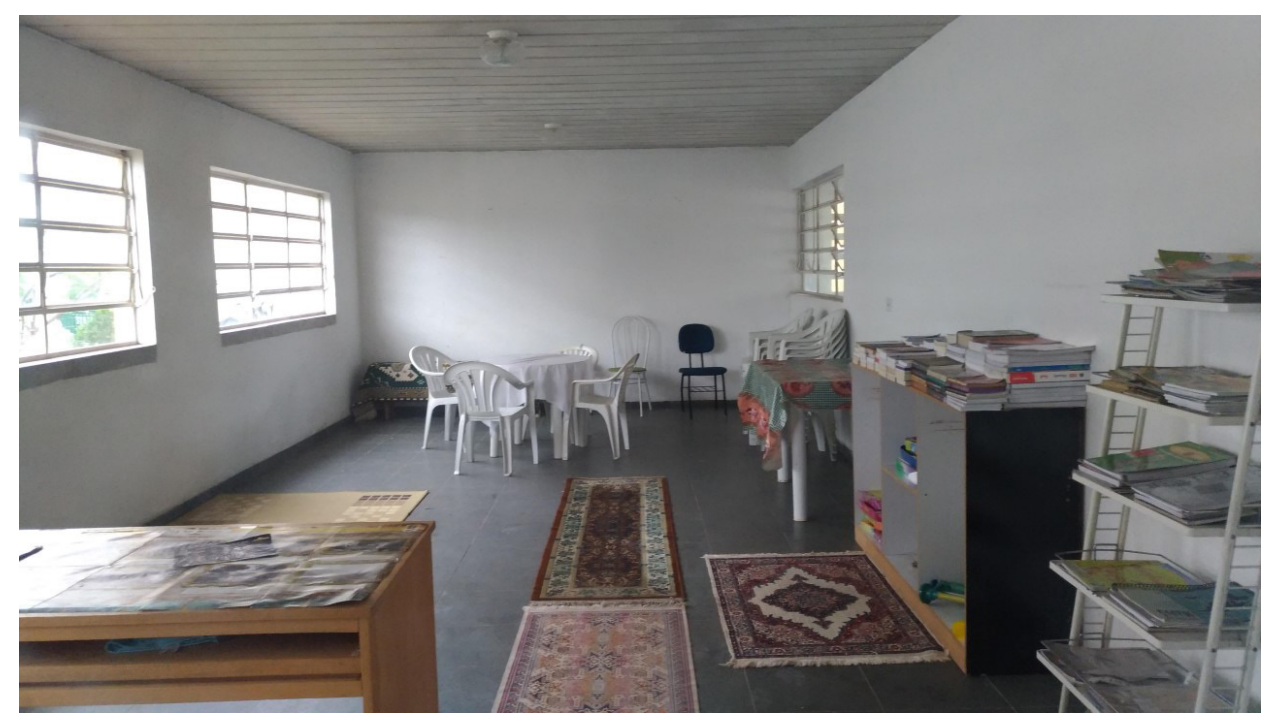

A concepção dos Condomínios previa, além dos projetos voltados para a habitação, ambientes de uso da comunidade, áreas institucionais, com acesso independente para atividades de programas da Prefeitura Municipal como Biblioteca, acesso à Internet e demais atividades sociais ${ }^{10}$. Esse caráter já se apresenta na figura $4 \mathrm{e}$ pode ser reforçado pela figura 9, a seguir que apresenta a área de reuniões dos condôminos do Condomínio G, proposto em projeto.

Os condomínios são formados por blocos lineares, divididos em módulos que se conectam e que possuem alturas variáveis. O número de pavimentos das edificações depende de seu escalonamento com relação à declividade do terreno: todos possuem pelo menos quatro pavimentos acima do térreo que, em determinadas situações serve de andar intermediário para um número de andares inferiores que varia de um a quatro. Dessa forma, as edificações são todas diferentes entre si. No térreo está localizada uma circulação coletiva que dá acesso às escadas e onde se localizam as áreas voltadas para atividades comunitárias como educação, lazer, centro comunitário e de convivência. Além disso, todos possuem unidades no pavimento térreo que cumprem a Norma Brasileira NBR 9050, referente à acessibilidade em edificações, mobiliário, espaços e equipamentos urbanos.

\section{Conclusão}

Conforme pode ser relacionado neste artigo, existem diversos problemas no que se refere à habitação social no Brasil e sua produção. Ações como as de urbanização de favelas na capital paulista vêm tanto na tentativa de sanar o déficit de moradias quanto na melhoria da qualidade das unidades habitacionais e da infraestrutura básica no entorno da habitação.

Em São Paulo, um exemplo desta ação é o Complexo Paraisópolis, proposto pela Secretaria de Habitação por volta de 2005, tendo concluído os trabalhos no que 
se refere às unidades habitacionais por volta do ano de 2012. Parte da premissa dos agentes envolvidos no processo era evitar a replicação do modelo usual de construção de habitação chamado, no momento, "Cingapuras" e propor novas soluções.

Neste contexto, foram propostos os Condomínios - denominados de A a G e projetados pelo escritório Elito Arquitetos, onde os Condomínios E e G foram certificados pelo Selo Casa Azul da CAIXA Econômica Federal. Ainda assim, as imagens trazidas bem como as descrições assinaladas apontam um conjunto de problemas que ainda permanecem - sobretudo o contexto no qual está inserido este Complexo. A realidade dos moradores é de convivência com grandes padrões de segregação, inseridos em um dos bairros mais caros da cidade de São Paulo, por um lado e na franja da segunda maior favela da cidade, por outro.

\section{Referências bibliográficas}

CASTILHO, J. V. de. A favelização do espaço urbano em São Paulo. Estudo de caso: Heliópolis e Paraisópolis. São Paulo: Faculdade de Arquitetura e Urbanismo, Universidade de São Paulo, 2013. 257 p.

CASTRO FILHO, H. A. R. de. Percepção de empresas construtoras em relação aos programas de classificação da sustentabilidade de projetos de construção habitacional: um estudo de caso do Selo Casa Azul Caixa. Porto Alegre: Universidade Federal do Rio Grande do Sul, Porto Alegre, 2013. $57 \mathrm{p}$

DENALDI, R. Políticas de Urbanização de Favelas: Evolução e impasses. São Paulo: Faculdade de Arquitetura e Urbanismo, Universidade de São Paulo, 2003. 229 p.

ELITO, Edson. Entrevista concedida a Ana Carolina Carvalho Figueiredo. São Paulo, dez. 2017.

FERNANDES, T. de O. Habitação Social nas metrópoles: Rio de Janeiro e São Paulo. Rio de Janeiro: Escola Politécnica, Universidade Federal do Rio de Janeiro, 2015. 203 p.

HASHIMOTO, Carlos. Entrevista concedida a Ana Carolina Carvalho Figueiredo. São Paulo, nov. 2016.

PIZARRO, E. P. Interstícios e interfaces urbanos como oportunidades latentes: O caso da Favela de Paraisópolis. São Paulo: Faculdade de Arquitetura e Urbanismo. Universidade de São Paulo, 2014. 370 p.

PREFEITURA DA CIDADE DE SÃO PAULO. Urbanização de favelas em foco: Experiências de seis cidades. São Paulo: Cities Alliance, 2008. 58 p.

PREFEITURA MUNICIPAL DE SÃO PAULO. 2017. Disponível em: <http://www.prefeitura.sp.gov. br/cidade/secretarias/habitacao/programas/index.php?p=141> Acesso em: jul. 2017.

PREFEITURA MUNICIPAL DE SÃO PAULO. Habitação de interesse social em São Paulo: desafios e novos instrumentos de gestão. São Paulo: Cities Alliance, 2008. 96 p.

RIBEIRO, E. M. A Política de Habitação Popular no Brasil em Tempos de Globalização Neoliberal. In: Jornada Internacional de Políticas Públicas, Questão Social e Desenvolvimento no Século XXI, 3., 2007, São Luís. Anais. São Luís: UFMA, 2007. 9 p.

SAMORA, P. R. Projeto de habitação em favelas: Especificidades e parâmetros de qualidade. São Paulo: Faculdade de Arquitetura e Urbanismo, Universidade de São Paulo, 2010. 348 p.

SÃO PAULO. Secretaria Municipal de Habitação. Prefeitura Municipal de São Paulo. HabitaSAMPA. 2018. Disponível em: <http://www.habitasampa.inf.br/>. Acesso em: jan. 2018. 
SÃO PAULO. São Paulo Projetos de Urbanização de Favelas - São Paulo Architecture Experiment [versão para o inglês Valadares Vasconcelos]. São Paulo, HABI - Superintendência de Habitação Popular/Secretaria Municipal de Habitação, 2010. $1^{\text {a }}$ edição.

SILVA, A. C. Políticas Públicas para Habitação de Interesse Social no Município de São Paulo: O Caso da Urbanização de Paraisópolis. In: URBFAVELAS, 2., 2016, Rio de Janeiro. Anais.... Rio de Janeiro: Letra Capital, 2017. p. 5 - 31.

WERNECK, R. M. O processo de urbanização da favela de Paraisópolis (SP): Desigualdade ou acesso ao direito habitacional. In: Colóquio Brasil-Portugal, 4., 2016. Anais... São Paulo: Universidade Presbiteriana Mackenzie, 2016. 